\title{
The Harmonized Social Cash Transfer Program in Zimbabwe: Achievements and Challenges
}

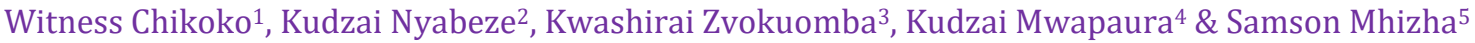 \\ ${ }^{1}$ Department of Social Work, University of Zimbabwe, Zimbabwe \\ 2Department of Social Work, Women's University in Africa (WUA), Zimbabwe \\ ${ }^{3}$ Department of Sociology, University of Johannesburg (UJ), South Africa and Senior lecturer at ZEGU \\ ${ }^{4}$ Department of Social Work, Reformed Church University (RCU) \\ ${ }^{5}$ Department of Applied Psychology, University of Zimbabwe \\ wchikoko@gmail.com
}

\begin{abstract}
The research article reviews the achievements and challenges that bewilder the harmonized social cash transfer (HSCT) program in Zimbabwe. World over HSCT programming has grown in terms of importance as a social protection service vehicle. Deploying a qualitative research design and documentary analytical framework corroborated by the capability approach, the study unpacks and brings to the fore the challenges and opportunities as nuances of HSCT programming in Zimbabwe. The study supports and adds another dimension to existing literature and challenges previous findings of HSCT programming in the Zimbabwean environment. Thus the study argues that HSCT programming in Zimbabwe registered noticeable achievements which make it a critical social protection program that ought to be integrated into the broader national framework of protecting the vulnerable groups. The study further argues that the HSCT program contributes immensely to raising the dignity of those on the margins through the promotion of resiliency and the general well-being of the communities. Thus the study recommends that the HSCT program in Zimbabwe be part of the government and not-for-profit organisations' comprehensive package for administering social protection services.
\end{abstract}

Keywords: Capability Approach, Harmonized Social Cash Transfer, Qualitative Documentary Analysis.

\section{Introduction}

There is a dearth or paucity of updated literature on the achievements and challenges associated with Zimbabwe's Harmonized Social Cash Transfer (HSCT) program. The social protection programs in Zimbabwe are anchored in various pillars Government of Zimbabwe (2016) and these include; social assistance, social insurance, labour market interventions, livelihoods support strategies, social support and care among others. The study aims to unravel the challenges and achievements of HSCT programming in Zimbabwe to establish new trends, developments and identify hidden dimensions that may not be shared in ordinary discourses. The research study deployed a documentary analysis compounded by the capability approach for the erudition of new thoughts. Thus the study's specific objectives are to establish how the HSCT program has been fairing in Zimbabwe, identifying areas of strength and weaknesses. Thus the research article, in its structure, delves on to the contextual, theoretical and methodological engagements in the first part and the last part gazes at the discussions and synthesis of the thoughts about HSCT programming in Zimbabwe.

Contextualising HSCT Programming: Examining social protection programs as cash transfer, Ninno et al. (2016) defined it in terms of policies, programs that help individuals, groups and communities to build resilience to daily and life risks. In addition, these policies and programs promote the achievement of equity. Patel (2015: 162) has defined social protection as "widely used as an umbrella term for a wider range of programs of both state and non-state actors and includes income security and access to social services". The term social protection is broad and covers formal and non-formal measures designed to protect people from life crises and increase their capabilities to meet their basic needs (Mupedziswa and Ntseane 2013, Kaseke and Dhemba 2007, Devereux 2007, Mpedi 2008, Midgely 2013). Social Protection programs, therefore, provide opportunities to vulnerable members of society (Ninno et al., 2016). They do this by offering or providing a basic income to the vulnerable and reducing the risks of poor households while enhancing opportunities for a better future (Ninno et al., 2016). The increases in poverty among children in Zimbabwe can be traced to the 1990 period a decade after the independence (Munro 2015).

Some of the key issues that increased childhood poverty included the introduction of structural adjustment programs such as the Economic Adjustment Program known as ESAP, economic meltdown, HIV and AIDS and 
the severe droughts of 1992, 1995, 2002 and 2008 among others (Mushunje and Mafico, 2010; Munro, 2015). Moreover, it was noted that during the year 2000, the Zimbabwean economy was severely affected by the recurrent drought, rising tensions over disagreements of distribution of land among other issues (Seidenfeld et al., 2016). Thus, by the late 2010s Chinyoka (2017) and later Mate (2018) observed that from 2000 to 2008, Zimbabwe had gone through major socio-economic and political developments. The significant features that characterised this period of extreme poverty included the high rate of unemployment, Operation Restore Order/Murambatsvina in 2005, land distribution, deindustrialisation and subsequent growth of the informal sector, resulting in hyperinflation, political bickering between the two major political players among others (Mate 2018). The 2000 to 2008 period was characterised by the huge suffering among the vulnerable members of Zimbabwean society. The impact of these socio-economic and political developments had enormous consequences for those already experiencing social deprivation. Within Zimbabwean society, this included people experiencing extreme poverty, elderly women, people with disabilities and children and youth. The acute socio-economic and political challenges severely affected the parentless children and children at risk in many ways.

These children could not meet their basic needs such as food, health, shelter among others (Ringson, 2017). The Government of Zimbabwe was perceived as being unable could address the poverty experienced by children (Mate 2018) and this was observed as more and more children started to live and work on the street to eke a living (Rurevo and Bourdillon 2003). During this period the street girls became more vulnerable to sexual exploitation, resulting in some girls engaging in transactional sex to survive life on the streets (Rurevo and Bourdillon 2003). To solve the poverty crisis and to address some of the socio-economic challenges faced by the vulnerable members of society, the Government of Zimbabwe through support from donors introduced the harmonised cash transfer program among other initiatives (Seidenfeld et al., 2016). The Government of Zimbabwe's national cash transfer program has been known as the Harmonised Cash Transfer (HSCT) (Chinyoka 2018; Seidenfeld et al., 2016). The HSCT program was started during the Government of National Unit characterised by a highly sensitive political environment among others (Seidenfeld et al., 2016; Chinyoka 2018). The HSCT program was introduced in 2011 by the Government of Zimbabwe's Ministry of Public Services Labour and Social Welfare through a pool funded managed by UNICEF (Seidenfeld et al., 2016; Kanengoni, 2016). The HSCT program also targeted labour constrained households that were food insecure (Seidenfeld et al., 2016; Chinyoka 2017).

The HSCT Program's main objectives included; enabling poor households to increase consumption levels above the poverty line, reducing the number of ultra-poor households, and helping beneficiaries avoid negative risk coping strategies (Seidenfeld et al., 2016). By February 2014, 55509 households twenty out of sixty-five districts that were covered in Zimbabwe (Seidenfeld et al., 2016). Mate (2018) further explains that the harmonised cash transfer program only covered ten percent (10\%) of those targeted districts. Therefore, it means that ninety percent of the households are left out even if they live in abject poverty. The program targeted households headed by the elderly (61\%), children (3\%), in addition, $81 \%$ of the households were female-headed ones (Seidenfeld et al., 2016). The HSCT program also targeted households of vulnerable members of society such as those with disabilities, orphaned children people living with HIV and AIDS, such that they could meet their basic daily needs (Seidenfeld et al., 2016). Drawing from the capability approach, through the harmonised cash transfer program the vulnerable members of society such as the elderly, orphans other vulnerable children are able to meet their basic needs. The cash transfer has been popularised as one of the key interventions in responding to the growing crisis of orphanhood in Sub Saharan Africa (Roelen et al., 2012). UNICEF (2015) estimates that by 2015, there were over 52 million orphans in the region.

To respond to the needs of these orphaned children in a context characterised by the collapse of extended, family systems and the HIV and AIDS pandemic, there was a need to introduce child-sensitive social protection programs in the name of cash transfer programs. The cash transfer programs have been popularised social welfare interventions in the majority of developing countries. Devereux et al. (2017) define social cash transfer as regular and non-contributory payments either in cash or kind for example vouchers or food. Devereux et al. (2017) added that payments are made by the Government of non-governmental organisations to poor people/individuals or households. The primary objective of social cash transfer is to decrease chronic or shock poverty through addressing social risk and or reducing economic vulnerability 
(Devereux et al., 2017). There is a further subdivision of cash transfer programs (Roelen et al., 2017). In other words, Roelen et al. (2017) came up with three different typologies of cash transfer programs. The first type is unconditional child grants, where income is provided to households of orphaned children (Roelen et al., 2017). The second category is programs that include the accumulation of physical and structural assets (Roelen et al., 2017). Some of the assets could include small livestock such as rabbits, chicken among others. Some of the programs that fall within this category include public works, and or human capital (Roelen et al., 2017).

This type is coined as a conditional cash transfer program. The third category is what Roelen et al. (2017) observed as a more integrated package of support. Roelen et al. (2017) give example graduation programmes as part of the integrated packages. The social transfer program includes various non-contributory welfare grants (Devereux et al., 2017). These include social pensions, disability grants, child support grants and family allowance (Devereux et al., 2017). The conditional social transfers can either be cash or kind basis (Devereux et al., 2017). The financial backing for cash transfer programs came from Western donors including the British Government through the DFID and from UNICEF (Seidenfeld et al., 2016). The harmonised cash transfer program became one of the pillars of the Child Protection Fund (UNICEF, 2010). However, cash transfer programs were not the panaceas for all those experiencing social exclusion.

Conceptual Framework-Capability Approach: Bussiere et al. (2016) noted that the capability approach was coined by Sen (2013). Sen (2013) defines the capability approach in terms of two major issues namely capabilities and functionality. Sen (2013) added that the approach focuses on ends, not means. In other words, the argument is that focusing on the means does not lead to capability development. Human beings should not see as consumers or as having needs rather as broadly as agents of change (Sen, 2013). They can change their circumstances around their lives (Sen, 2013). Human beings have the capabilities, and these are demonstrated when they can think, assess, evaluate, resolve, inspire, agitate and through these means thus reshaping the world (Sen 2013). However, Robeyns (2005) observed that the capability approach is a multidimensional concept and can be used to evaluate different aspects of human's wellbeing. Robeyns (2005) added that some of the aspects included the following; poverty, inequality among others. In addition, the capability approach provides a framework that shows how freedom is connected to people's capabilities (Sen 2013). An individual's capability can better develop when they have concrete experiences, opportunities and resources to draw upon when navigating pathways towards the desired outcome.

Such situations are common among street children where their capability is affected because of the limitedness of resources. It may be proposed that the child's agency becomes a key feature or characteristic of the capability approach, affecting their ability to pursue life goals which they value. Nussbaum (2003 \& 2011) revisited Sen's social justice/capability approach. She argues that Sen's 'perspective of freedom' is too vague. Nussbaum added that some of the freedoms affect others by limiting them. However, she argues that some of the freedoms are important as others are trivial among others. Nussbaum argued that human dignity is very important in human lives. She extended Sen's original proposition by listing ten central capabilities that represent, in her view, a dignified life. These included according to Bussiere; bodily health, bodily integrity, sense, imagination and thought, emotions, practical reasons, affiliation, other species, play, and control over one's environment (Bussiere et al., 2016). Returning to Nussbaum's capability perspective, children and other vulnerable members of Zimbabwean society's capabilities and functioning are severely affected as the HSCT program in the country is marred with multiple challenges. The children and other vulnerable members of Zimbabwean society do not live dignified life as a result of the challenges associated with the HSCT program.

\section{Research Methodology}

Qualitative documentary analysis was adopted in this study. Bowen (2009: 28) defines document analysis as "a systematic procedure for reviewing or evaluating documents both printed and electronic material." The scholar furthers that the examination and interpretation process is to elicit meaning, gain understanding and develop empirical knowledge. The documents that may be used for systematic evaluation of a study take a variety of forms (Bowen, 2009). Like any other research method, document analysis has advantages and limitations. Bowen (2009) observed that some of the advantages include; coverage (Yin, 1994), exactness, stability, efficiency, availability, cost-effectiveness, lack of obtrusiveness among others. However, document 
analysis has a number of limitations and these include; insufficient detail, biased selectivity, low irretrievability among others (Yin, 1994; Bowen, 2009). The documentary analysis involved a desk review of various literature around child-sensitive social protection programs in Zimbabwe. The literature review focused on, legislations, policies, research reports, academic books and or articles among others. The conclusions made in this article were based on purposively identified themes namely, social cash transfer, social protection programs, child sensitiveness among others.

\section{Research Findings}

This section delves into the presentation and discussion about the nuances of harmonised social cash transfer within the Zimbabwean environment. The section is divided into two parts the first one deliberating on the achievements while the second part focuses on the challenges ensured in the administration of harmonised social cash transfer.

HSCT and the Promotion of Resiliency: The research findings suggest that the HSCT program promoted resiliency among households that were observed resonated with Seidenfeld et al. (2016) argument that the program led to improvements in a number of domains and areas that are associated with promoting resiliency. These areas included; increased agricultural assets (sickles and hoes) and livestock (donkeys, goats), diversification of income sources for example growing of different crops and enterprising in nonfarming activities among others. Thus the study, through its empirical evidence points to the reduction of debts among the beneficiaries, significant risks of food insecurity and absolute poverty. Seidenfeld et al. (2016) further argue that shocks and risks included by drought and crop failure and price increases tend to be reduced by harmonised social cash transfer programming. This part of the study findings is further highlighted in the sections below as they relate to human existence.

Adolescent Development and Increased in Violence Awareness: The study also established that HSCT programming significantly contributed towards adolescent development particularly those who were under the project administration. The study observed and witnessed a steady transition from adolescent hood to adulthood in the first year of HSCT program implementation suggested that there was safe migration into adulthood. The study holds a similar epistemological gaze with Seidenfeld et al. (2016) and argues that some domains like reducing the likelihood of early pregnancies among female youths, delaying sexual debut and also early marriages were visible and notable. Thus this study argues that HSCT programming positively contributes towards safer sex behaviours among youths and adolescents which include practices such as the increase in condom use and reduction in forced sex. Capability is affected, therefore, when people live in a resource-constrained environment, characterised by and resulting in limited opportunities.

Field-based evidence also showed that HSCT programs provided opportunities for raising not only sexual related problems but awareness on violence and protection issues. The HSCT program in Zimbabwe promoted an increase in violence awareness campaigns in the various communities as the field workers took the frontline responsibility of sharing information. The study holds the argument that a continuous and sustainable approach to HSCT contributes to societal transformation and positions children for the takeover of leadership in society. There was an increase in the reporting of violence cases the police and community leaders in line with the awareness companies carried out particularly in districts that implemented the program. Seidenfeld et al. (2016) noted the same developments in their comparative study of districts that implemented the HSCT program against those that did not implement it. Based on this evidence, this study argues that HSCT is a practical vehicle for information sharing and awareness-raising in communities.

Increased Investment in Children and Other Vulnerable Members of Society: The increased investment in children and other vulnerable members of society has been one of the benefits associated with the HSCT program in Zimbabwe. While Nyawasha (2012) made a general position about the positive relationship of HSCT programming and child welfare, this study further noted and argues that orphans who participated in HSCT got access to money to meet their basic needs including food, clothes educational related complimentary such as stationery and school uniforms. Whilst Nyawasha (2012) observed that 68 per cent of the participants in a study had indicated that the HSCT program significantly impacted in helping address the socio-economic challenges faced by orphaned children. This study noted holistic improvement in orphaned 
children's welfare transforming from being beggars of food to enrolling on schools. Provision of basic social protection services to children in difficult circumstances as well as other vulnerable members of society enhances their dignity. This is a central aspect of HSCT programming which even Sedenfeld et al. (2016) acknowledges the psychosocial benefits of HSCT programming among vulnerable members of society. The study concurs with Nyawasha (2012) that when the social-psychological dignity of the vulnerable is raised, they are able to make meaningful contributions and decisions that affect their day to day lives. These observations and arguments are augmented by the contradictory nuances and dimensions of HSCT programming that are discussed below.

Human Capital Related Challenges of Implementing HSCT Programs: An observation of note about the implementation of the HSCT programs had to do with human capital resources or requirements. The research findings suggest that effective HSCT program implementation was marred by human resources challenges. While the issue of staff retention remains an aspect characterising many organisations the world over, the Zimbabwean economic 'melt down' environment contributed to the skills flight in both the government department of social development and local not-for-profit organisations. The study established that competent and experienced employees complained of low salaries, hence, the challenge of low level of motivation. The chain reaction points to the limited skills in the administration of such a delicate social protection program increased case load for the available employees with limited experience that result in poor programming. Similar observations were noted by Mushunje and Mafico (2010) and Sedenfeld et al. (2016) who carried related studies in Zimbabwe. A classic example was that of social welfare officers employed at the District level by the Department of Social Development who were supposed to be twelve but were only four. Above all, they had just joined the department from the universities, hence, the issues of experience, skills and staff compliment affected the administration of HSCT negatively.

Coverage and Targeting Criteria: It is evident that the HSCT program phase 1 targeted 10 districts of Zimbabwe despite the vastness of the country. Similar observations were noted by Chinyoka (2017) and that by late 2011 during the first scale-up period, the HSCT program had benefited 19, 827 households only. The study also established that harmonised cash transfer program in Zimbabwe has challenges relating to limited funding as a household get between USD 10 and 25 per month when the Zimbabwe food poverty line is pegged at USD 30 per person per month (Chinyoka 2017). In other words, the cash transfers which were administered to beneficiaries were far less below both the food poverty line and the total consumption poverty line. Chinyoka (2018) raised the same position in the 2018 survey and argued that Zimbabwe is the least comparably with neighbouring countries in Southern Africa, that is, South Africa (95\%), Botswana (85\%) and Namibia (65\%). As such the study established that the coverage of the HSCT programme was very much limited as many poor households were excluded from being beneficiaries. The HSCT program was accessing limited funding from both Government and UNICEF through the Child Protection Fund which targeted ten percent of poor households in each district and was mathematically an increase particularly compared to the traditional public assistance program, but on a practical level, it remained to have limited coverage. This study also found out that the formalised HSCT program was out of reach to children living in the streets. These vulnerable had no household to be identifiable with hence the program did not extend its coverage to them.

Limited Integration with Other Social Protection Programs: The field-based evidence suggest that the HSCT program was not well integrated with other social protection programs such as Basic Education Assistance Module (BEAM), Assisted Medical Treatment Order (AMTO) and the Public Assistance programs administered in the department of social development. During the first phase of the HSCT program, there was no coordination as noted by Sedenfeld et al. (2016 despite the direct influence between HSCT and other programs such a BEAM. The study established that while BEAM programming has been community-based, the community dynamics at the grassroots level made it totally independent of HSCT program targeting. As a result of such poor integration and or coordination of social protections efforts, the efforts that were supposed to take advantage of each other were weakened, hence, the success or achievements of the HSCT program became compromised. The study holds the argument that coordination problems of such noble programs that benefit the vulnerable groups may be a reflection of poor social protection governance and lack of commitment from politicians as discussed below. 
Lack of Political Will: The study also established that HSCT programming was affected by a lack of political will from bureaucrats and politicians. As already noted by Chinyoka (2018), the post Government of the National Unity government era witnessed a shift in the investment of social protection programs in Zimbabwe. Politicians who used to prioritise social protection programming as part of their social and political responsibility shifted to electioneering and consolidation of political power at the party level. ZANU $\mathrm{PF}$ being the only political party in government was interested in agrarian-based social protection programs such as the agricultural input scheme which did not only receive a lesser budget but was not accessible by the vulnerable groups in society. As a result of limited political will, the funding of the HSCT program was whittled down as the Government of Zimbabwe focused on Command Agriculture programming, input scheme and other non-cash social transfer related programs. The study argument about lack of political will was concretised by the Government of Zimbabwe's failure to honour a funding commitment they had reached with donors of contributing 50/50 funds toward the HSCT program. This left the donor to fund an in the proportional figure which eventually left a big gap whose effects could only be felt at the beneficiary level.

The researcher's engagements with study interlocutors showed that some politicians and bureaucrats did not hold the issue of spending much money on a social protection project. They held negative attitudes towards the HSCT program. Similar observations were noted and documented by Chinyoka (2018) during the Government of National Unity in 2013 as members of parliament shared their negative thoughts about investing in the HSCT program. The politicians were of the view of giving vulnerable members of Zimbabwean society food instead of cash (Chinyoka 2018). This study again noted these negative energies of policymakers towards the HSCT program, hence, an avalanche of conflicting social protection priorities. The research article, therefore, argues that the Government of Zimbabwe, directly and indirectly, seem to be more interested in the funding of the BEAM program while the donors' community show preference towards the HSCT program. The consequence of the contradictions and inconsistencies in thought and direction of programming leaves the vulnerable members of society at a loss.

\section{Discussion and Synthesis}

As already highlighted above, the HSCT program in Zimbabwe has been associated with positive impacts and drawing from the capability approach, it is arguable that the HSCT program in Zimbabwe enhanced dignity among vulnerable members of society. The HSCT program expanded the capabilities of the vulnerable members of society as there was increased investment in children. Through the promotion of resiliency, the HSCT program facilitated that the vulnerable members of society were able to adapt positively in the face of adversities, shocks among others. Therefore HSCT as part of community social protection raises peoples' capabilities (Roelen et al., 2017). Taking it further from the capability approach, Samuel and Stavropoulou (2016) argue that the total of material support of those in difficult circumstances is that their socialpsychological well-being improves. Some of the psychosocial benefits included; improved mental health, reduction in household stress levels. The Kenyan trials were used to further elaborate on this point and state that unconditional transfer of cash to the vulnerable increases happiness and life satisfaction among beneficiaries. Another capability approach scholar, Samuel and Stayropoupou (2016) share our view through the Malawi cash transfer case study in which the program contributed to the reduced psychological distress.

Among schoolgirls by $17 \%$ under the conditional cash transfer and $38 \%$ benefit in the unconditional cash transfer. Utilising the capability approach, the cash transfer program enhances the well-being of the beneficiaries through improved psychosocial well-being. Covarrubias' et al. (2012) work in Malawi also speaks to this Zimbabwean study in that beneficiaries of the HSCT program are able to invest in productive assets and livestock. Covarrubias et al. (ibid) added that because of the social cash transfer there was an increase in the number of households with goats and chicken as 52 and $59 \%$ respectively which is equivalent to the Zimbabwean study. The beneficiaries of the social cash transfer program significantly reduced hunger and increased average meals per day in their households similar to Adato and Basset (2009) study in Zambia. The Zambian case shares common threads with this study in that in both cases, beneficiaries of the HSCT program improved their nutrition status as they consumed fruits, vegetables, fats and protein. The consumption of milk, meat, fats, fruits and sugar increased as comparably with non-beneficiary households. Related to the improved nutritional status are the positive impacts on the education of children. The study 
agrees with Adato and Basset (2009) that families under this program are able to pay for the school expenses of their children and the same children's school attendance is consistent with normalcies.

Adato and Basset 2009 use the South Africa example to highlight this point and posit that where the Child Support Grant has been implemented there was an 8.1point increase in school enrolment among six-year-old children and also 1.9 points for those that were aged seven years. The other dimension of the HSCT program as already alluded to are the challenges associated with it. Drawing from the capability theoretical framework, the children and other members of the Zimbabwean society do not live a dignified life because of the challenges associated with the HSCT program. The capabilities and functioning of the children and other vulnerable members are seriously affected, for example, when street children of the Harare Central Business District are or were left of the HSCT program it demonstrates that the children were denied their basic services/needs. It also highlights that the street children remained in childhood characterised by extreme childhood poverty, and some adopted risk coping mechanisms. Some of the risk coping mechanisms could include engaging in substance abuse, transactional sex work among, others (Chikoko, 2014). Similarly, this study shares Bosworth et al. (2016) observations that the social cash transfer program in Kenya had some limitations because of irregular and late disbursements of funds, lack of an objective mechanism to differentiate the poverty level of the targeted beneficiaries.

During the pre-pilot evaluation period, there was a significant inclusion error (Bosworth, et al., 2016). Devereux et al. (2017), discuss the various targeting mechanisms on social cash transfers and these include; means-testing, proxy means testing, geographic targeting, community-based targeting, self-targeting, multiple mechanisms, categorical targeting among others. However, the authors observed that targeting is always a big issue in many social protection programs. The social cash transfer program has received several criticisms through an in-ward looking approach from some of its proponents like Molyneux et al. (2016) who acknowledge that centrally about HSCT programming are the exclusion and inclusion eras at implementation stages. This study noted such eras particularly during target which ultimately may disadvantage deserving people or and incorporate non-deserving ones into the program. We argue that these eras are a consequence of the scheme design and implementation eras. Drawing from the capability approach, when social cash transfer programs are characterised by some of the above-mentioned challenges or problems, then the targeted households do not reach their full potential in life. A further critique of HSCT programming from a capability approach is also raised by Granlund (2020) who argues that the feminist lenses of the social cash transfers are opaque which reinforces a materialistic role or assumes that women are 'bearers of benefits to others' and in addition to using women 'to fix the world'.

The critique is associated with the conditional cash transfer program which predominantly has female, beneficiaries (Granlund 2020). Through conditional cash transfer programs, women are seen as being forced to comply with time-consuming obligations to benefit or receive cash benefits (Grandlund 2020). Some of the obligations included; taking babies and children for health checks, assuring school attendance (Grandlund 2020). This argument is seen as reinforcing and or reproducing inequality and the genderised division of labour which in most instances places women and or mothers with more burden of child care (Grandlund 2020). Many critics have questioned the underlying rationale of the cash transfer program (Molyneux et al., 2016). Some have doubted whether the cash transfer program is as effective as suggested in talking poverty. The small size of the amount of the cash transfer, limited linkages to training and or survival or livelihoods skills for adult household members presents few opportunities around the minimum safety net (Slater 2011; Molyneux et al., 2016). Ellis (2012) noted that during the pilot experiences of Malawi and Zambia, the cash transfer programs did not lift the targeted households from poverty. The author added that the program seemingly addressed some of the critical poverty, which could be life-threatening. Utilising the capacity approach, when the cash transfer program fails to pull people or households from poverty, then it becomes worrisome as the same households would struggle to enhance their wellness.

\section{Conclusion and Recommendations}

The research article has brought to the fore the complex nuances of the HSCT program in Zimbabwe by highlighting the multiple strengths and weaknesses in the administration of the program. The study did not only show the debates about program implementation but also showed why the HSCT program challenges 
are outweighed by the achievements. By adopting the capability approach, the study further foraged on why the HSCT program is compatible with other existing social protection services and how beneficiaries at the grassroots level may be advantaged by government and not-for-profit organisations working together. An integrated approach to social protection compounded with political will on the part of bureaucrats and politicians have far-reaching positive consequences on children and adults experiencing distress. The study has shown that communities and individuals experience a reduction in cases and or incidences of violence, promotion of resiliency and adolescent development among others. Thus the study propagates the argument that HSCT programming is a progressive and pro-poor social protection program that ought to be reviewed often to always come up and execute best practices.

Recommendations: The study provides a number of recommendations to improve the performance of harmonised social cash transfer programs. These include;

- There is a need for public sector reform coupled with long term development assistance for organisational change and behavioural changes at various levels such as national, provincial and district as noted by Schubert and Slater (2006) to enhance the capacity of social welfare services.

- There is a need for lobbying and advocating Government of Zimbabwe and other donors such as DFID to avail more financial and technical resources towards social protection programs.

- There is a need to come up with a sustainability strategy for social protection programs in Zimbabwe. This is on the basis that a bigger chunk of the HSCT program's financial resources is donor-driven.

- There is also a need to build capacity on policymakers, practitioners, academics and researchers on social protection issues. For example, capacity strengthening or building programs for social welfare services through the provision of computers, vehicles, training courses, administrative budgets among others (Schubert and Slater 2006).

- The provision of social protection programs such as the HSCT program from a human rights-based approach to all deserving or vulnerable members of society.

- There is a need to improve in targeting and coverage criteria of the HSCT program. Thus ensuring that the most vulnerable members of society benefit from the social protection programs. For example, the street children as a special constituency of children in Zimbabwe have not been benefitting from HSCT programs.

- There is a need to combine the social protection program with skills training. This will go a long way in terms of ensuring that the vulnerable members of society can earn a living through selling their labour.

- There are cost-benefit considerations as noted by Schubert and Slater (2006), given the limitedness of budgets in low-income countries like Zimbabwe. The administrative costs should be kept as low as possible.

- There is a need to review upwards of the monthly payout of 25 USD per household as noted by Nyawasha (2012) considering that the pay-out is meagre in relation to the basic needs of the beneficiaries.

- There is a need to integrate and or coordinate the HSCT with other social protection programs like Basic Education Assistance Module, Assisted Medical Treatment Orders etc. This will go a long way in terms of coordination of social protection programs and leverage on that to reduce duplication of efforts and resources.

\section{References}

Adato, M. and Bassett, L. (2009). Social protection to support vulnerable children and families: The potential of cash transfers to protect education, health and nutrition, AIDS Care, 21(1), 60-75.

Bosworth, J., Alviar, C., Corral, L., Mwasiaji, W., Ochieng, S., Pearson, R., Pozarny, P. \& Wiseman, W. (2016). The cash transfer programme for orphans and vulnerable children: The catalyst for cash transfer in Kenya cited in From Evidence to Action: The story of cash transfers and impact evaluation in SubSaharan Africa, The Food and Agriculture Organisation of the United Nations, The United Nations Children's Fund \& Oxford University Press, Madison, Oxford.

Bowen, G. A. (2009). Document analysis as a qualitative research method. Qualitative Research Journal, 9(2). 
Bussiere, C., Sicsic, J. \& Pelletier-Fleury, N. (2016). Simultaneous effect of disabling conditions on primary health care use through a capability approach Social Science and Medicine, 154, 70-84.

Chikoko, W. (2014). Substance abuse and Commercial Sex Work among adolescent street children of Harare Central Business District Journal of Social Development in Africa, 29, 2.

Chinyoka, I. (2017). Poverty, changing political regimes and social cash transfers in Zimbabwe WIDER Working Paper 2017/88

Chinyoka, I. (2018). How and why do states provide for children? Comparing social grants for families with children in Southern Africa, unpublished PhD thesis, Department of Sociology, University of Cape Town, South Africa.

Devereux, S. (2007). Social pensions in Southern Africa in the Twentieth Century Journal of Southern African Studies, 33(3).

Devereux, S., Masset, E., Sabates-Wheeler, R., Samson, M., Rivas, A. M. \& te Lintelo, D. (2017). The targeting effectiveness of social transfer Journal of Development Effectiveness, 9(1), 162-211.

Dhemba, J. (2013). Social Protection for the Elderly in Zimbabwe: Issues, Challenges and Prospects in the African Journal of Social Work, 3(1).

Ellis, F. (2012). We are all poor here': Economic differences, social divisiveness and targeting cash transfer in Sub Saharan Africa Journal of Development Studies, 48(2), 201-214.

Granlund, S. (2020). The Promise of Pay Day: Exploring the role of state cash transfers in post-apartheid rural South Africa, unpublished Doctoral thesis, Swedish University of Agricultural Sciences, Uppsala.

Kanengoni, J. (2016). Perceptions of the recipients of social welfare assistance about the effectiveness of Zimbabwe's welfare assistance programme: The case of Gutu district in Zimbabwe, unpublished Masters of Arts in Social Development Dissertation, Department of Social Work, School of Human and Community Development, University of the Witwatersrand, South Africa.

Mate, R. (2018). Social policy and social spending in Zimbabwe: 1980 to 2015, United Nations Research Institute for Social Development Working paper 2018-8

Molyneux, M., Jones, N. \& Samuels, F. (2016). Can cash transfer programs have transformative effects? The Journal of Development Studies, 52(8), 1087-1098.

Mpedi, L. G. (2008). The role of religious values in extending social protection: A South African perspective Acta Theologica, 1.105(23).

Munro, L. T. (2015). Children in Zimbabwe after the long crisis: Situation analysis and policy issues Development Southern Africa, 32(4), 477-493.

Mushunje, M. T. \& Mafico, M. (2010). Social protection for orphans and vulnerable children in Zimbabwe: The case for cash transfer International Social Work, 53(2), 261-275.

Mupedziswa, R. \& Ntseane, D. (2013). The contribution of non-formal social protection to social development in Botswana Development Southern Africa, 30(1), 84-97.

Patel, L. (2015). Social welfare and social development, (2nd edition), Oxford University Press, Southern Africa, Cape Town.

Ringson, J. (2017). Community-based coping strategies for orphans and vulnerable children in Zimbabwe, unpublished $\mathrm{PhD}$ thesis, University of the Witwatersrand, South Africa.

Roelen, K., Delap, E., Jones, C. \& Chettri, H. K. (2017). Improving child wellbeing and care in Sub Saharan Africa: The role of Social Protection Children and Youth Review, (73), 309-318.

Robeyns, I. (2005). The capability approach: a theoretical survey Journal of Human Development, 6(1), 93117.

Rurevo, R. \& Bourdillon, M. F. C. (2003). Girls: The less visible street children of Zimbabwe Children, Youth and Environment, 13(1), 1-20.

Nyawasha, T. S. (2012). Evaluating the effectiveness of the Cash Transfer Programme for Orphaned Children in Zimbabwe Journal of Sociology and Social Anthropology, 3(2), 145-151.

Ninno, C., Coll-Black, S. \& Fallavier, P. (2016). Social Protection Programmes for Africa's Dryland International Bank for Reconstruction and Development/The World Bank, Washington, DC.

Nussbaum, M. (2003). Capabilities as fundamental entitlements: Sen and Social Justice Feminist Economics, 9(2-3), 33-59.

Nussbaum, M. C. (2011). Creating capabilities- The Human Development Approach, $1^{\text {st }}$ Edition, Harvard University Press, Cambridge. Mass.

Samuels, F. \& Stavropoulou, M. (2016). 'Being able to breathe again': The effects of cash transfer programmes on psychosocial well-being, The Journal of Development Studies, 52(8), 1099-1114. 
Seidenfeld, D., Dumba, L., Handa, S., Muwoni, L. \& Reeves, H. (2016). Using evidence to overcome political and economic challenges starting a national unconditional cash transfer programme cited in From Evidence to Action: The story of cash transfers and impact evaluation in Sub-Saharan Africa, The Food and Agriculture Organisation of the United Nations, The United Nations Children's Fund \& Oxford University Press, Madison, Oxford.

Sen, A. (2013). The ends and means of sustainability Journal of Human Development and Capabilities, 14(1), 620.

Schubert, B. \& Slater, R. (2006). Social cash transfers in low-income African countries: Conditional or unconditional? Development Policy Review, 24(5), 571- 578.

Slater, R. (2011). Cash transfers, social protection and poverty reduction International Journal of Social Welfare, 20(3), 250-259.

Yin, R. K. (1994). Case study research: Design and methods (2nd Ed), Thousand Oaks, CA: Sage. 